\title{
Preformative molt in Neotropical Cardinalidae
}

\author{
Santi Guallar ${ }^{1}$ (D) $\cdot$ Rafael Rueda-Hernández ${ }^{2}$ (D) $\cdot$ Peter Pyle $^{3}$ \\ Received: 5 June 2020 / Revised: 9 September 2020 / Accepted: 14 September 2020 \\ (C) Sociedade Brasileira de Ornitologia 2020
}

\begin{abstract}
Neotropical Cardinalidae consists of 40 species in 10 genera that have diversified across the Americas. We provide quantitative information on the preformative molt of 21 Cardinalidae species of seven genera, plus one Thraupidae species placed within Cardinalidae until recently. From 155 preformative molt cards, we calculated molt extent estimates, computed frequencies of molt patterns, and summarized observed frequencies of wing-feather replacement in wing diagrams. We found 17 species with partial preformative molts, four species with eccentric preformative molts (outer but not inner primaries replaced), and one species with a complete preformative molt. Preformative molt extent and patterns were similar within Cardinalidae genera, including genera with Nearctic representatives, such as the complete preformative molt of Northern Cardinal Cardinalis cardinalis or the eccentric molt of Passerina buntings. Our results cover an important gap in the knowledge of the natural history of Cardinalidae, generate important criteria to determine the age of Neotropical Cardinalidae, and provide essential information to test hypotheses on the ecology and evolution of molt in this passerine family.
\end{abstract}

Keywords Age determination $\cdot$ Bayesian bootstrapping $\cdot$ Molt extent $\cdot$ Molt patterns

\section{Introduction}

The preformative molt occurs within the first year of life (or molt cycle) of birds and is unique to this cycle (Howell et al. 2003). It has been found to vary substantially among avian species, from absent (no feathers replaced) to complete (all feathers replaced), but is partial or incomplete in most species. There is much interest in what phylogenetic and environmental factors influence the extent of the preformative molt both

Communicated by Carla S. Fontana

Supplementary Information The online version of this article (https:// doi.org/10.1007/s43388-020-00024-z) contains supplementary material, which is available to authorized users.

Santi Guallar

sguallar@yahoo.com

https://museuciencies.cat/area-cientifica/departaments-cientifics/ vertebrats/

2 Departamento de Biología Evolutiva, Facultad de Ciencias, Universidad Nacional Autónoma de México, Av. Universidad 3000, Delegación Coyoacán, 04510 México, DF, Mexico

3 Institute for Bird Populations, Petaluma, CA, USA within and among bird families. For example, the preformative molt extent in passerines has been reported to correlate to breeding latitude (Kiat and Izhaki 2016), migration distance (Kiat et al. 2019a), delayed plumage maturation (Kaspar Delhey pers. comm.), habitat (Willoughby 1991), and even climate change (Kiat et al. 2019b).

Cardinalidae is a family of small to mid-sized passerine birds, which comprises 52 species in 11 genera (Klicka et al. 2007; Billerman et al. 2020). These species are distributed throughout the Americas, with 40 species residing strictly in the Neotropical region, three species breeding in both the Neotropical and the Nearctic regions, and nine species migrating between these regions to breed (Billerman et al. 2020). Most species in the family Cardinalidae are sexually dichromatic, Caryothraustes being the only exception. Many longdistance migrants show striking seasonal plumage changes through prealternate molts (e.g., species within Piranga and Passerina), and males in species of all genera except Cardinalis exhibit delayed plumage maturation (i.e., do not acquire a definitive-like appearance following the preformative molt).

Extensive basic natural history information of most Cardinalidae species has been documented (Billerman et al. 2020), especially of those species that migrate to Nearctic regions to breed (e.g., Pyle 1997a and references therein). 
However, molt strategies in Neotropical Cardinalidae are poorly understood, with more than half of the species lacking any information (Billerman et al. 2020). Thus, the objective of this study is to provide preformative molt information of Neotropical species in the family Cardinalidae (see Table 1 for species and scientific names). Having quantitative information on the preformative molt extent of Neotropical Cardinalidae will not only increase our knowledge on the biology of this family and enhance our ability to age Cardinalidae, it will also allow us to test ecological and evolutionary hypotheses (e.g., Rohwer et al. 2005; de la Hera et al. 2013).

\section{Methods}

We obtained information on preformative molt in 22 species, 21 species of Neotropical Cardinalidae (seven genera), and one species of Thraupidae, Yellow-shouldered Grosbeak Parkerthraustes humeralis, placed within Cardinalidae until recently (Table 1).

We completed 142 molt cards from specimens of Neotropical Cardinalidae deposited in five museum collections in North America and Europe (see Acknowledgments) and added 13 molt cards from a large published dataset (Guallar and Jovani 2020). Molt cards present quantitative data on molt of individual wing, tail, and body feathers, as well as date and locality of collection or capture and museum where specimens are deposited (Suppl. Mat. Table S1).

\section{Molt data}

We summarized molt information for every species following Guallar et al. (2018). For estimates of molt extent among wing feathers and rectrices, we scored non-active molt data on one wing and the tail, specifying which wing feathers and rectrices were replaced. We used established aging criteria to identify first-year birds having undergone the preformative molt, as based on feather coloration, shape, and wear (Jenni and Winkler 1994; Pyle 1997a; Suppl. Mat. Fig. S1). We aged Vermilion Cardinals Cardinalis phoeniceus based on juvenile specimens that were halfway or more through the complete molt sequence, as in Northern Cardinal Cardinalis cardinalis (Pyle 1997a). Based on date of collection and feather wear, we carefully considered whether or not any feathers may have been replaced during a first prealternate molt. Replaced formative feathers were scored 1 and retained feathers 0 . The nine visible primaries, six secondaries, three tertials, three alula feathers, nine primary coverts, carpal covert, 10 greater coverts, eight median coverts on the upper wing, and the 12 rectrices were scored individually. Replaced lesser coverts were scored as an approximate percentage of the feathers forming the tract, and then expressed as a decimal (from 0 to
1). Wing-feather molt extent was computed as the sum of feather scores for the left wing, and ranged from 1 to 50 (the latter corresponding to complete molt). Tail-feather molt extent was computed as the sum of rectrix scores for the left half of the tail, and ranged from 1 to 6 .

Wing-feather molt patterns are classes of observed phenotypes grouped under certain criteria of similarity (Guallar and Jovani 2020). We computed observed frequencies for each of the preformative wing-feather molt patterns present. Individuals within and among species can show more than one pattern. Briefly, there are nine wing-feather molt patterns described thus far (see details in Table 1 and Fig. 1 in Guallar and Jovani 2020): (1) complete (full replacement); (2) abridged I (retention of a variable number of secondaries); (3) abridged II (retention of a variable number of primary coverts); (4) eccentric (retention of a variable number of inner primaries, outer secondaries, and primary coverts); (5) general (replacement of coverts and tertials from leading to trailing edge); (6) proximal (replacement of coverts and tertials, prioritizing feathers closer to the body); (7) inverted (replacement of inner secondaries and secondary coverts from trailing to leading edge); (8) limited (replacement of lesser and median coverts); and (9) reduced (replacement of one to a few tertials and/or secondary coverts).

Observed frequencies of preformative wing-feather replacement for each species were computed as the arithmetic mean score of every individual wing-feather (mean percentage for the block of lesser coverts) following Guallar et al. (2018).

\section{Statistical analyses}

We estimated sample mean and $95 \%$ density intervals of both wing-feather and tail-molt extents for every study species with $n>1$. We applied Bayesian bootstrapping using default settings (4000 iterations), as implemented in the R library bayesboot (Bååth 2016). Bootstrapping is a resampling technique not limited by the assumptions of parametric approaches, and therefore is adequate for small datasets and/or variables which do not reasonably fit a known distribution. Bayesian statistics add the advantage of allowing direct probabilistic statements. However, statistics cannot account for low sample size and limited geographic sampling (see Table 1). Therefore, inference from these analyses inherits the limitations of the sampled information, and variations for many species are far from being represented.

Because species' evolutionary histories are closer within than among genera, congeneric species are expected to be more similar than non-congeneric ones. To compare molt extent among species within the genera we sampled, we used ANOVA and post hoc analyses. ANOVA were not phylogenetically corrected due to the small number of comparisons (genera in our dataset contain information for up to four 


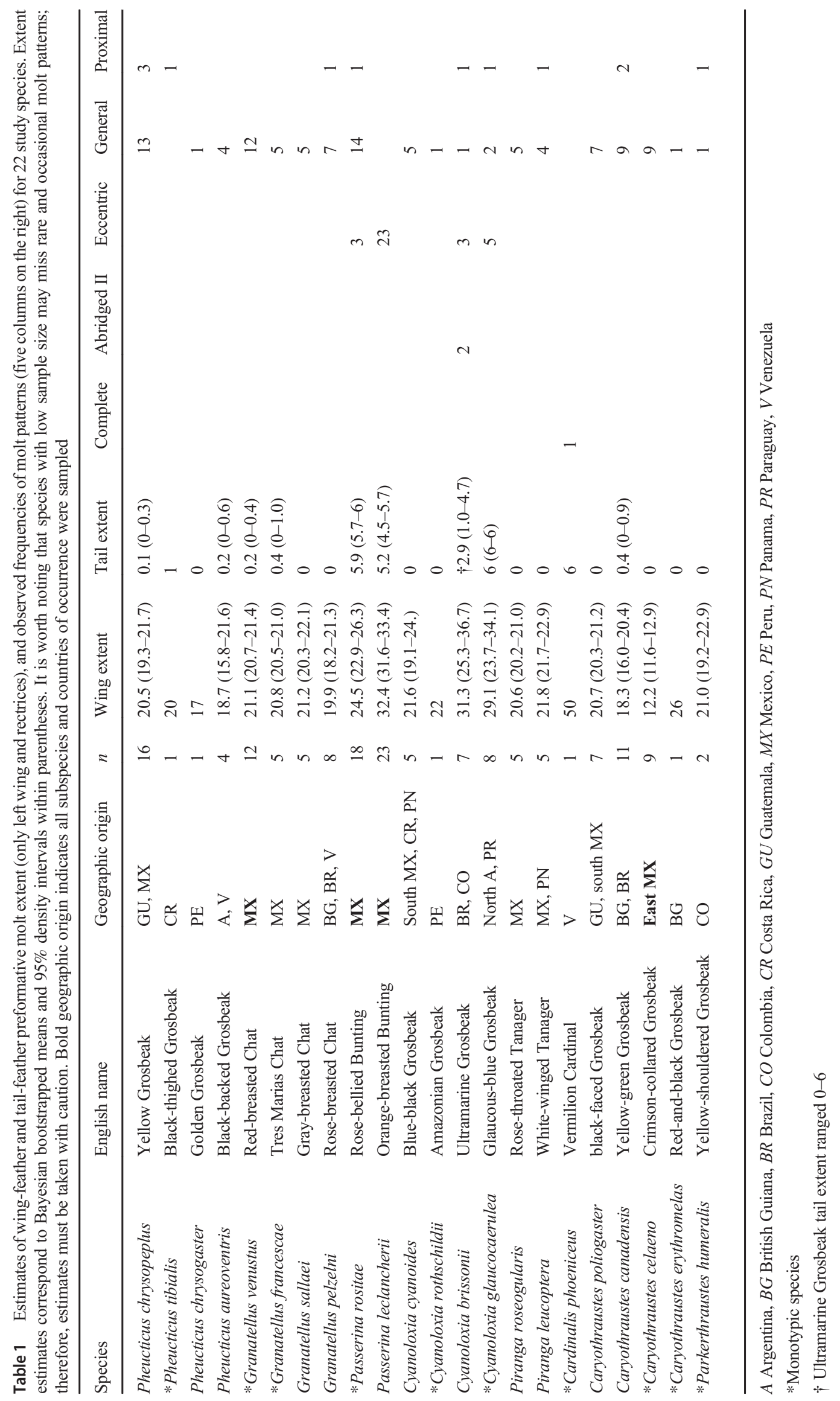


species). All analyses were carried out within the R environment (R Core Team 2019).

\section{Results}

Of our 22 study species, mean preformative wing-feather molt extent ranged from 12.2 in the Crimson-collared Grosbeak Caryothraustes celaeno to 50 in the Vermilion Cardinal (Table 1). Species within genera tended to have similar wing-feather molt extents. Thus, for the six genera comprising more than one species in our dataset, we only found significant differences within Passerina and Caryothraustes (Table 2). Within Passerina, Orange-breasted Bunting Passerina leclancherii replaces eight more remiges on average than Rose-bellied Bunting Passerina rositae. Within Caryothraustes, Crimson-collared Grosbeak has significantly smaller molt extent than the other three species in our dataset (Tukey test, $P<0.001$ ). Despite two of the four Cyanoloxia species regularly replacing remiges, we did not find significant differences within this genus (Tukey test, $P>0.05$ ) as a consequence of the wide overlap among the four species in our dataset (Fig. 1, Table 1).

Median molt extent in our dataset was 23.4. We used this value as a reference point to rank and compare relative molt extents among species and genera (Fig. 1). Thus, fifteen species in the genera Pheucticus, Granatellus, Piranga, Caryothraustes, and Parkerthraustes had mean wing-feather molt extents below the median, whereas six species in the genera Cyanoloxia, Passerina, and Cardinalis had mean molt extents above this value. Genera Passerina, Cyanoloxia, and Caryothraustes had species that scored both below and above this value (Table 1).

Individuals in 17 species did not replace rectrices during the preformative molt, whereas individuals from five species replaced them all (Table 1, Suppl. Mat. Table S1). Ten species had at least some individuals with incomplete rectrix replacement, often limited to the central pair.

Table 2 ANOVA results showing comparisons of wing-feather molt extent among species within genera. All three Cardinalis species (not included in this analysis) undergo a complete preformative molt (Pyle 1997a). Note that species with $n=1$ cannot be included in the comparisons

\begin{tabular}{llll}
\hline Genus & Statistic & $P$ & Species sampled \\
\hline Pheucticus & $F_{1,18}=1.14$ & 0.538 & 2 \\
Granatellus & $F_{3,26}=1.16$ & 0.344 & 4 \\
Passerina & $F_{1,39}=65.57$ & $<0.001$ & 2 \\
Cyanoloxia & $F_{2,17}=2.29$ & 0.203 & 3 \\
Piranga & $F_{1,8}=2.88$ & 0.128 & 2 \\
Caryothraustes & $F_{2,24}=19.85$ & $<0.001$ & 3 \\
\hline
\end{tabular}

We found five patterns associated with the preformative molt (Table 1). The complete pattern was found in Vermilion Cardinal. The abridged II pattern was found in Ultramarine Grosbeak Cyanoloxia brissonii. The eccentric pattern was only found in four species of two genera (Passerina and Cyanoloxia). The general and proximal patterns were present in all species except Orange-breasted Bunting and Vermilion Cardinal. We did not find the abridged I, inverted, limited, or reduced molt patterns in any species.

Although variation among species in molt pattern was relatively high, variation within species tended to be low. Thus, for 17 species with $n>1$, nine species (53\%) presented only one molt pattern, five showed two patterns, two showed three patterns, and only one species, the Ultramarine Grosbeak, showed four patterns (Table 1). Because of the low sample sizes, the absolute frequencies at which molt patterns are present in our dataset are uncertain; however, relative frequencies are likely representative of the expected variation. Thus, most individuals showed the general molt pattern (69\%), followed by the eccentric molt pattern (23\%), and the proximal molt pattern (7\%), with only two Ultramarine Grosbeaks showing the abridged II molt pattern (1\%).

All species in our sample replaced lesser, median, and inner greater coverts. The frequency of replacement of the remiges was similar within genera. Thus, Cardinalis species replaced all remiges, and Passerina and Cyanoloxia replaced many but not all remiges (22\% Rose-bellied Bunting actually retained all remiges, and Blue-black Cyanoloxia cyanoides and Amazonian Cyanoloxia rothschildii Grosbeaks never replaced primaries or secondaries). On the other hand, Pheucticus and some Caryothraustes showed a high frequency of tertial, but no other remex replacement. The remaining genera retained all remiges (Fig. 2, Suppl. Mat. Fig. S1). Thus, Passerina and Cyanoloxia are likely to show molt limits within remiges. The other five Neotropical genera in the family Cardinalidae (except Cardinalis, which undergoes a complete preformative molt) would typically show molt limits within alula feathers, greater coverts, and/or tertials, or between these groups and adjacent tracts.

\section{Discussion}

We have described extent, patterns, and frequency of replacement of wing-feather molt in 21 Neotropical Cardinalidae species and one close relative, Yellow-shouldered Grosbeak, currently placed within Thraupidae. Along with descriptions from six other Nearctic migrant species published elsewhere (Pyle 1997a; Guallar et al. 2009, 2016, 2018), two-thirds of the preformative molt of Neotropical species in this family are now documented.

Although uncertainty of estimates may be high for species with small sample sizes (McCarthy 2007), and infrequent or 
Fig. 1 Estimated mean (points) and $95 \%$ bootstrapped intervals (lines) of wing-feather preformative molt extent for 22 study species. Dashed red line depicts the median molt extent in for species with $n>1$ our dataset. Intervals only shown

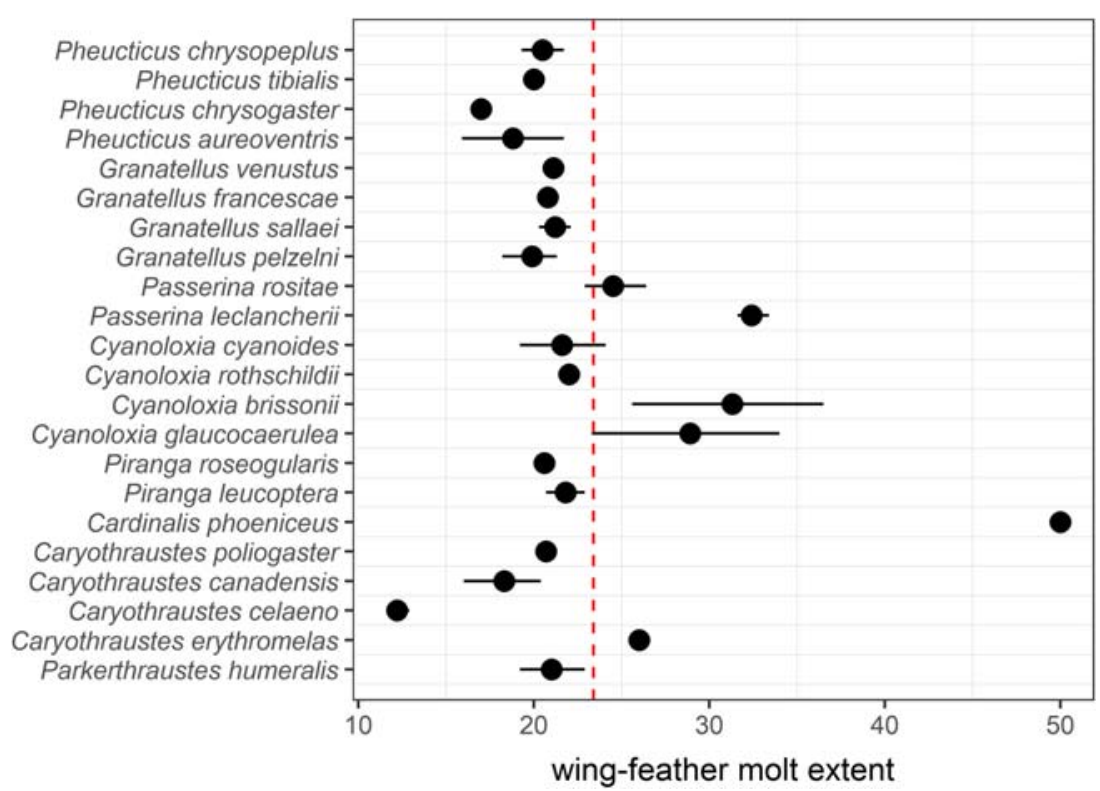

occasional wing-feather molt patterns may remain undetected for some of them, our results are consistent with the scarce information published on the preformative molt of Neotropical Cardinalidae species (Johnson and Wolfe 2018). Moreover, they support the expected similarities within passerine genera (Jenni and Winkler 1994; Pyle 1997a). For example, Neotropical species within the genera Pheucticus and Granatellus have similar estimates of molt extent and patterns (Table 1), and estimates of the extent of wing-feather molt in Neotropical species also overlap those published for northtemperate species within Cardinalis, Passerina, Pheucticus, and Piranga (Pyle 1997b). These similarities suggest phylogenetic inertia likely associated with shared ancestry and comparable natural histories and/or environments.

However, we also detected some differences within genera. The general pattern (a molt pattern that does not include primaries) is dominant in Rose-bellied Bunting, instead of the eccentric pattern (which includes outer primaries and inner secondaries), which is pervasive in the remaining Passerina species (Rohwer 1986; Thompson 1991; Young 1991; Pyle 1997a). This is intriguing because this species forages and nests in the same lowland areas as Orange-breasted Buntings that largely undergo an eccentric molt (Thompson and Leu 1995; Guallar and Jovani 2020). This contrast might represent an evolutionary transition toward a smaller investment in preformative molt (unpubl. data). Reasons behind this shift are obscure, but we propose four non-exclusive explanations: (1) hardening of the remex structure (e.g., via pigmentation; Burtt 1979; Bonser 1995); (2) differential resource allocation during juvenile plumage growth, so that juvenile remiges become more resistant than the feathers that will be replaced during the preformative molt (de la Hera et al. 2010); (3) increased tolerance to flight-efficiency loss (e.g., modifying behavior; Vega-Rivera et al. 1998); and (4) increased ability to reduce abrasion through behavioral adaptations (e.g., reducing insolation or contact with abrasive vegetation; Willoughby 1991).

Passerina species are not the only example of within-genus differences. Within Cyanoloxia, Ultramarine and Glaucousblue Cyanoloxia glaucocaerulea Grosbeaks have a more extensive preformative molt, and the former presents more molt patterns than its congeners (Table 1), resembling more the patterns of Blue Bunting Cyanocompsa parellina, formerly considered congeneric. Thus, ultramarine and Glaucous-blue Grosbeaks may also have undergone an evolutionary transition toward a greater investment in preformative molt. Preformative molt extent also varies within Caryothraustes, from 12 in Crimson-collared Grosbeak to 26 in Red-and-black Grosbeak Caryothraustes erythromelas. Similarly, noticeable variations in preformative molt extents have been observed in other Neotropical passerine genera with similar natural histories (e.g., Empidonax, Vireo, Turdus, Habia, and Spinus; Pyle 1997a, b; Guallar et al. 2016, 2018). Further research is needed to identify environmental correlates and somatic effects to explain within-genera differences, along with possible evolutionary explanations.

This work documents preformative molt for 21 Cardinalidae species and one closely related Thraupidae species. However, this documentation is handicapped by two deficiencies that overall plague the knowledge on the preformative molt of Neotropical birds (Rueda-Hernández et al. 2018). First, it presents low sample sizes for 17 of the study species. The smaller the sample size is, the narrower the molt variation one may capture within species. While some species are known to present a wide variation both in preformative wing-feather molt pattern and extent (e.g., 
Pheucticus grosbeaks
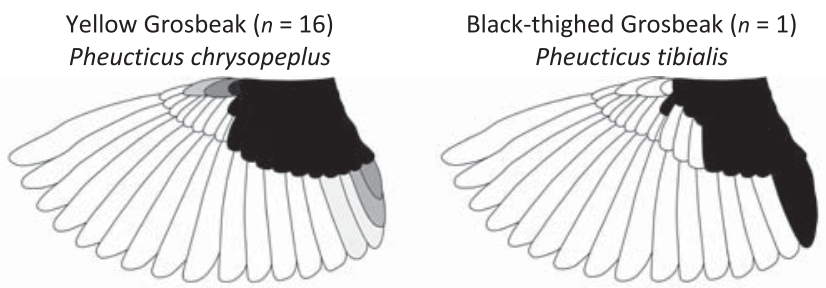

Granatellus chats

Red-breasted Chat $(n=12)$ Granatellus venustus
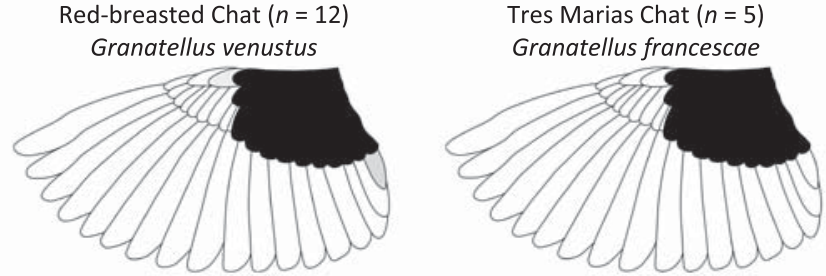

Passerina buntings
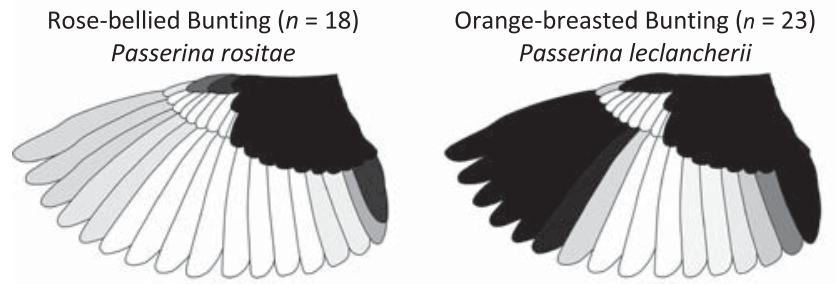

Cyanoloxia grosbeaks
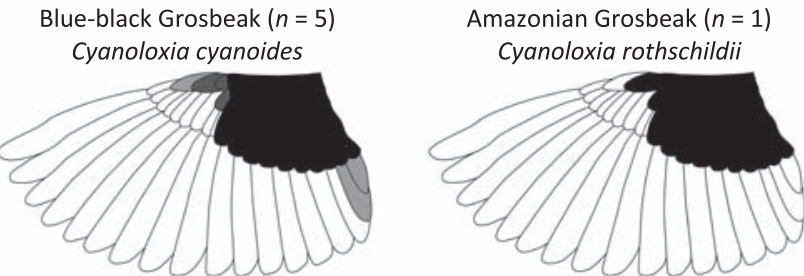

Fig. 2 Frequency of preformative wing-feather replacement in 22 study species. Gray shades on wing diagrams depict observed replacement frequencies $($ white $=0$, black $=100$; see legend on bottom row) .

Blue-black Bunting; Guallar and Jovani 2020), others are known to be quite homogeneous (e.g., many species in the family Parulidae; Guallar and Jovani 2020). This pattern can also be detected within our study species (check dispersion around the mean in Fig. 1). Thus, Red-breasted Chat Granatellus venustus presents a very small variation despite its moderate sample size, whereas Ultramarine and Glaucousblue Grosbeaks present a large variation despite their low sample sizes (Fig. 1, Table 1). Since molt is one of the main natural history traits of passerines, molt changes can have profound effects on many other traits. Thus, most of the pattern and variation that we observe are a consequence of both
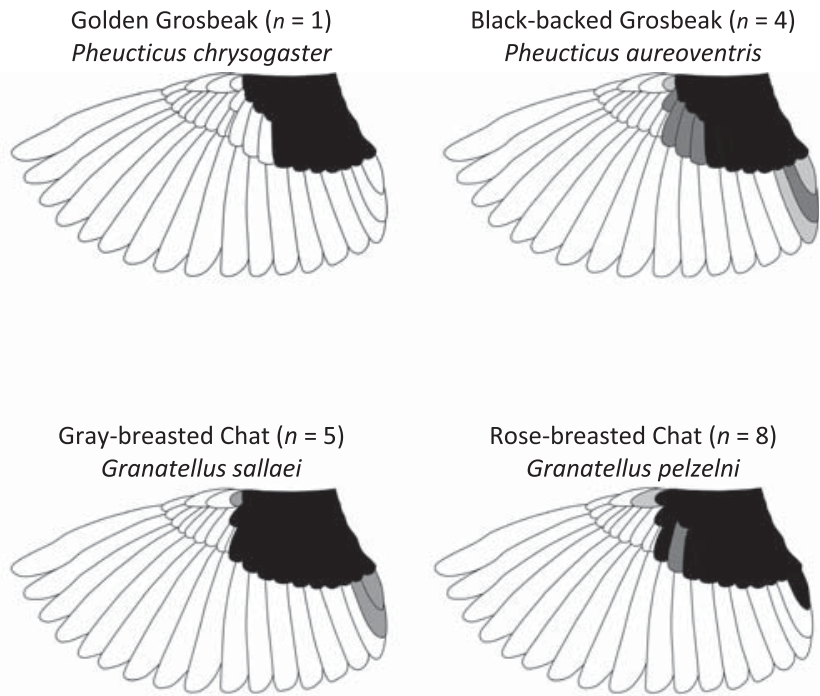
Piranga tanagers

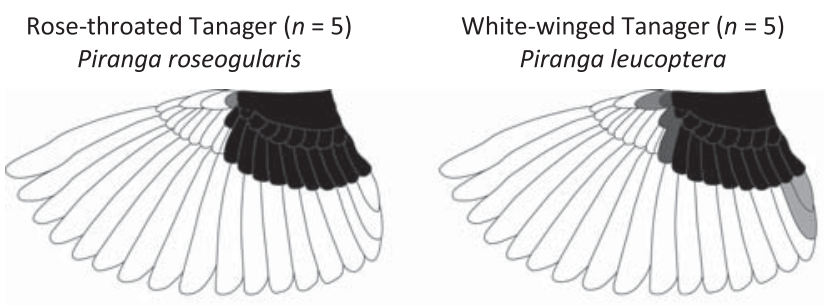

Cardinals

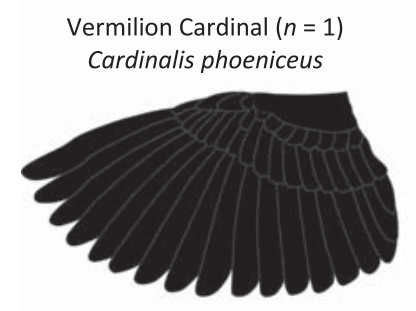

Caryothraustes grosbeaks

Black-faced Grosbeak ( $n=7$ ) Caryothraustes poliogaster

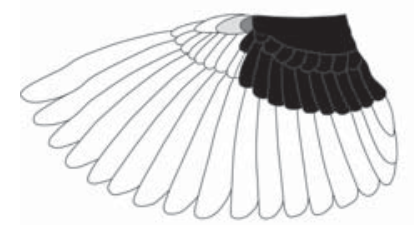

Parkerthraustes grosbeak (Thraupidae)
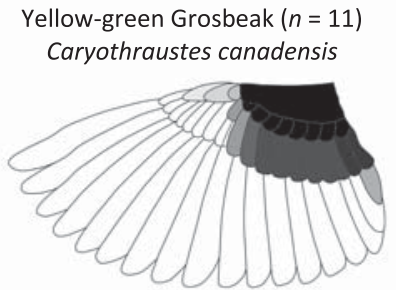
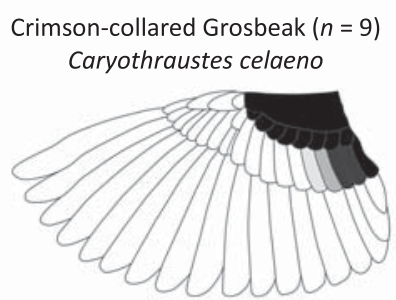

Red-and-black Grosbeak ( $n=1$ ) Caryothraustes erythromelas

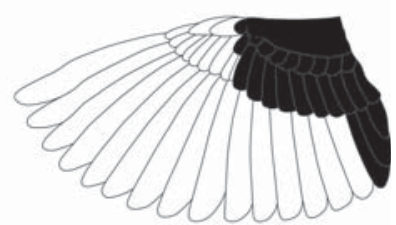

Yellow-shouldered Grosbeak $(n=2)$ Parkerthraustes humeralis
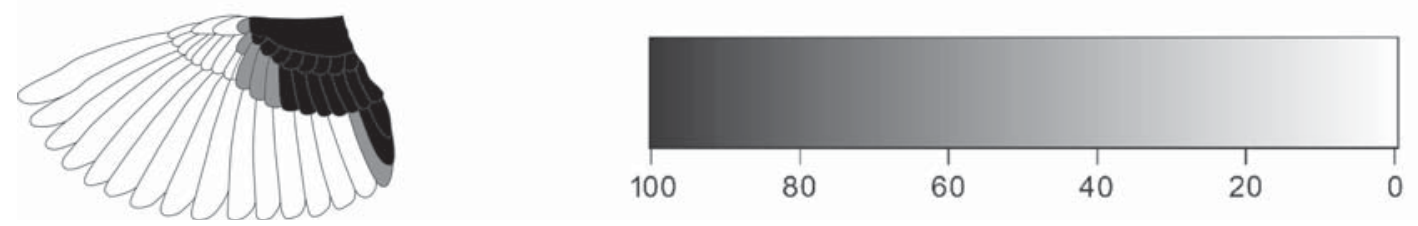

Fig. 2 (continued)

within species, we hypothesize that specialists will present smaller preformative molt variation than generalists.

The shortcomings we mentioned recommend caution before applying the results of this study. However, two lines of evidence makes us confident about the validity of our findings: (1) we found consistent results with the preformative molt information published for the Amazonian and Yellowgreen Caryothraustes canadensis Grosbeaks (Johnson and Wolfe 2018); and (2) our data were consistent within genera (Table 2), both in this study and when compared with other well-studied congeneric species (i.e., Pheucticus, Passerina, Piranga, Cardinalis; Pyle 1997a; Table 2). We speculate that the interaction among the factors known to have influenced the evolution of passerine preformative molt and the strength of the potential constraints (e.g., food resources) may vary sufficiently among closely related species to explain certain divergences that we have found (e.g., between the two Passerina buntings). For example, delayed plumage maturation is fairly common within Cardinalidae, and is known to be one of the most influential factors in the evolution of passerine preformative molt (Kaspar Delhey pers.comm.). Detectable differences between the plumage of juveniles and adults can be easily achieved simply by decreasing molt extent, thus acting as a signal of lower status, and reducing aggressive interactions with older conspecifics (Senar 2006; Guallar and Figuerola 2016). Further research on plumage, habitat, solar exposure, and migratory behavior within the family Cardinalidae may also help explain some of this variation. 
Acknowledgments We thank the following for assistance and access to specimen collections: Maureen Flannery, California Academy of Sciences, San Francisco; Carla Cicero, Museum of Vertebrate Zoology, Berkeley; Bentley Bird, American Museum of Natural History, New York; Dr. Javier Quesada, Museu de Ciències Naturals de Barcelona; Dr. Adolfo Navarro and M.C. Fanny Rebón, Museo de Zoología Alfonso Herrera; and Dra. Patricia Escalante and M.C. Marco Gurrola, Colección Nacional de Aves, Mexico City. Constructive comments by three anonymous referees helped improve this manuscript.

Author contributions All authors contributed to the study conception, data collection, and study design. Analyses were performed by S.G. The first draft of the manuscript was written by S.G., and all authors commented on previous versions of the manuscript. All authors read and approved the final manuscript.

\section{Compliance with ethical standards}

Conflict of interest R. R-H. received a grant from Dirección General de Asuntos de Personal Académico-UNAM.

Informed consent Authors agreed with the content, gave explicit consent to submit the manuscript to Ornithology Research, and obtained consent from the reserves and museums where the data was gathered.

\section{References}

Bååth R (2016) Package 'bayesboot'. An implementation of Rubin's (1981) Bayesian bootstrap. Version 0.2.1. https://github.com/ rasmusab/bayesboot. Accessed 30 December 2019

Billerman SM, Keeney BK, Rodewald PG, Schulenberg TS (eds) (2020) Birds of the world. Ithaca: Cornell Laboratory of Ornithology. https://birdsoftheworld-org.proxy.birdsoftheworld.org/bow/home. Accessed 20 May 2020

Bonser RHC (1995) Melanin and the abrasion resistance of feathers. Condor 97:590-591. https://doi.org/10.2307/1369048

Burtt EH (1979) Tips on wings and other things. In: Burtt EH (ed) The behavioral significance of color. Garland STPM, New York, pp 75110

de la Hera I, Pérez-Tris J, Tellería JL (2010) Migratory behavior and differential resource allocation between wing and tail feathers in a passerine bird. Auk 127:647-652. https://doi.org/10.1525/auk. 2010.09120

de la Hera I, Reed T, Pulido F, Visser ME (2013) Feather mass and winter moult extent are heritable but not associated with fitness-related traits in a long-distance migratory bird. Evol Ecol 27:1199-1216. https://doi.org/10.1007/s10682-013-9639-x

Guallar S, Figuerola J (2016) Factors influencing the evolution of moult in the nonbreeding season: insights from the family Motacillidae. Biol J Linnean Soc 118:774-785. https://doi.org/10.1111/bij.12784

Guallar S, Jovani R (2020) Wing-feather moult phenotypes differ between the preformative and prealternate episodes and along passerine phylogeny. Ibis 162:778-786. https://doi.org/10.1111/ibi.12798

Guallar S, Santana E, Contreras S, Verdugo H, Gallés A (2009) Paseriformes del Occidente de México: morfometría, datación y sexado. Museu de Ciències Naturals de Barcelona, Barcelona

Guallar S, Ruiz-Sánchez A, Rueda-Hernández R, Pyle P (2016) Molt strategies of ten Neotropical forest passerine species. Wilson J Ornithol 128:543-555. https://doi.org/10.1676/1559-4491-128.3. 543
Guallar S, Ruiz-Sánchez A, Rueda-Hernández R, Pyle P (2018) Preformative wing molt in 23. Neotropical resident passerine species. Ornitol Neotrop 29:S3-S10

Jenni L, Winkler R (1994) Moult and ageing of European passerines. Academic Press, London

Johnson EI, Wolfe JD (2018) Molt in Neotropical birds: life history and aging criteria. CRC Press, Boca Raton

Kiat Y, Izhaki I (2016) Why renew fresh feathers? Advantages and conditions for the evolution of complete post-juvenile moult. J Avian Biol 47:47-56. https://doi.org/10.1111/jav.00717

Kiat Y, Izhaki I, Sapir N (2019a) The effects of long-distance migration on the evolution of moult strategies in Western-Palearctic passerines. Biol Rev 94:700-720. https://doi.org/10.1111/brv.12474

Kiat Y, Vortman Y, Sapir N (2019b) Feather moult and bird appearance are correlated with global warming over the last 200 years. Nat Commun 10:2540. https://doi.org/10.1038/s41467-019-10452-1

Klicka J, Burns K, Spellman GM (2007) Defining a monophyletic Cardinalini: a molecular perspective. Mol Phyl Evol 45:1014 1032. https://doi.org/10.1016/j.ympev.2007.07.006

McCarthy MA (2007) Bayesian methods for ecology. Cambridge University Press, Cambridge

Pyle P (1997a) Identification guide to North American birds. Part I Columbidae to Ploceidae. Slate Creek Press, Bolinas

Pyle P (1997b) Molt limits in north American passerines. North Am Bird Bander 22:49-90

R Core Team (2019) R: a language and environment for statistical computing. R Foundation for Statistical Computing, Vienna

Rohwer S (1986) A previously unknown plumage of first-year Indigo Buntings and theories of delayed plumage maturation. Auk 103: 281-292. https://doi.org/10.1093/auk/103.2.281

Rohwer S, Butler LK, Froehlich DR, Greenberg R, Marra PP (2005) Ecology and demography of east-west differences in molt scheduling of Neotropical migrant passerines. In: Greenberg R, Marra PP (eds) Birds of two worlds: the ecology and evolution of migration. Johns Hopkins University Press, Baltimore, pp 87-105

Rueda-Hernández R, Guallar S, Ruiz-Sánchez A, Pyle P (2018) The molt issue: where do we go from now. Ornitol Neotropl 29:S1-S2

Senar JC (2006) Color displays as intrasexual signals of aggression and dominance. In: Hill GE, McGraw KJ (eds) Bird coloration: function and evolution. Harvard University Press, Harvard, pp 87-136

Thompson CW (1991) The sequence of molts and plumages in Painted Buntings and implications for theories of delayed plumage maturation. Condor 93:209-235. https://doi.org/10.2307/1368938

Thompson CW, Leu M (1995) Molts and plumages of Orange-breasted Buntings (Passerina leclancherii): implications for theories of delayed plumage maturation. Auk 112:1-19. https://doi.org/10.2307/ 4088762

Vega-Rivera JH, McShea WJ, Rappole JH, Haas CA (1998) Pattern and chronology of prebasic molt for the wood thrush and its relation to reproduction and migration departure. Wilson Bull 110:384-392. https://doi.org/10.2307/4163963

Willoughby EJ (1991) Molt of the genus Spizella in relation to ecological factors affecting plumage wear. Proc Western Found Vert Zool 4: 247-286

Young BE (1991) Annual molt and interruption of the fall migration for molting in Lazuli Buntings. Condor 93:236-250. https://doi.org/10. 2307/1368939

Howell SNG, Corben C, Pyle P, Rogers DI (2003) The first basic problem: a review of molt and plumage homologies. Condor 105:635653. https://doi.org/10.1093/condor/105.4.635

Publisher's note Springer Nature remains neutral with regard to jurisdictional claims in published maps and institutional affiliations. 